\title{
Estrogenic Endocrine Disruption in Switzerland: Assessment of Fish Exposure and Effects
}

\author{
Patricia Burkhardt-Holm, Helmut Segner, Richard Burki, Armin Peter, Sara Schubert, \\ Marc J.-F. Suter, and Mark E. Borsuk
}

\begin{abstract}
Estrogenic exposure has been reported to occur in Swiss rivers, and there is concern that reduced reproductive health, caused by disturbances of the endocrine system, may contribute to the observed decline in brown trout catch. Consequently, we aimed to determine if disturbances of the endocrine system do occur in wild brown trout (Salmo trutta) in Switzerland and, in the affirmative case, if these might affect trout population status. Our first task was to characterize the estrogenicity of Swiss midland rivers that receive effluents from sewage treatment plants (STP). Next, we performed a set of laboratory and field exposure experiments aimed at elucidating how estrogens affect sexual development and reproductive parameters as estrogen-sensitive targets in the life cycle of brown trout. Subsequently, we assessed the demographic status of brown trout populations in the field which were exposed to the cumulative impact of estrogen-active compounds and other stressors. Finally, we integrated the data into a life-cycle model to predict potential population-level consequences of the (xeno)estrogenic exposure. The estrogenicity of 18 Swiss midland rivers was characterized bioanalytically by applying the YES bioassay to water samples and by measuring plasma vitellogenin (VTG) levels in resident brown trout. Generally, estrogenic contamination of the rivers appears to occur only locally and at comparatively low levels (0.2-2 ng/l $17 \beta$-estradiol equivalents). In laboratory experiments, potential disruptive effects of estrogens on gonadal differentiation and reproduction of brown trout were investigated. The estrogen-sensitive window of brown trout gonad differentiation was found to differ from other salmonid species. Feminisation of the developing gonads occurred only after exposure to rather high estrogen concentrations. Analysis of VTG mRNA levels indicated that the yolk may accumulate environmental estrogens and act as a long-term reservoir. The experiments to study the effects of prolonged estrogen exposure on reproduction of mature brown trout showed that, while VTG was induced at low concentrations (20 ng/l estrone (E1), 2 ng/l 17 $\beta$-estradiol (E2) and 400 ng/l 4-nonylphenol (NP)), effects on reproductive parameters such as fertility became evident only at the higher dose (100 ng/l estrone, $10 \mathrm{ng} / \mathrm{l} 17 \beta$-estradiol and $4000 \mathrm{ng} / \mathrm{l}$ 4-nonylphenol). For the field study, the river Lützelmurg (Canton Thurgau) was selected as our study site. This river is impacted by the estrogen-active effluents of one sewage treatment plant (STP). Estrogenic levels in the river were found to be highly variable over time, but showed a distinct difference between sites upstream and downstream from the STP effluent - a difference which was also reflected by the VTG levels of caged and resident brown trout. From the brown trout demographic data, it is evident that factors other than estrogen exposure, including habitat quality, strongly influence population structure. The results from the modelling supported this finding and showed that the trout population in the Lützelmurg is likely to be more sensitive to changes of survival rates in the first winter and beyond than to changes in early life stage survival or reproductive parameters. From the overall results of our project, we conclude that a significant influence of estrogenic contamination on brown trout population densities in the majority of Swiss rivers appears not to be likely.
\end{abstract}

Keywords: Brown trout · Endocrine disruptor - Estrogenic exposure $\cdot$ Fish population $\cdot$ Sewage treatment plant

${ }^{*}$ Correspondence: Prof. Dr. P. Burkhardt-Holm University of Base

Man - Society - Environment

Department of Environmental Sciences

Vesalgasse 1

$\mathrm{CH}-4051$ Basel

Tel.: +41612670402

Fax: + 41612670409

E-mail: patricia.holm@unibas.ch

\section{Introduction}

In Switzerland, as well as in numerous other countries, evidence for the presence of environmental estrogens in the aquatic environment and the exposure of fish and other wildlife has been reported. ${ }^{[1,2]}$ Due to a decline of brown trout catch in the last 20 years by up to $60 \%$, there is concern that disturbances of the endocrine system may be causing a reduced reproductive health in trout that is contributing to this decline. ${ }^{[3,4]}$
This concern was decisive for the initiation of the project SAFE, a multidisciplinary project aimed at determining whether disturbances of the endocrine system do occur in wild brown trout in Switzerland, and, in the affirmative case, how these disturbances may affect brown trout population health and density.

The first hypothesis of the project addressed the exposure situation: The exposure of river water and the inhabiting wildlife to estrogenic compounds in Switzerland 
is in a range that (a) can be measured and (b) is reflected in elevated vitellogenin levels, a biomarker of exposure in wild brown trout. Secondly, we hypothesized that estrogens at concentrations observed in Swiss rivers impair reproductive parameters, such as sexual differentiation, fertility, fecundity, and offspring survival. This hypothesis is derived from laboratory and field observations on the consequences of estrogenic exposure on developmental and reproductive parameters of wild fish populations (for a review:[5]). Thirdly, we hypothesized that estrogenic effects on individual development and reproduction will translate to the population level. The available evidence for population-level effects of estrogenic contamination is still scant, ${ }^{[6,7]}$ although recent studies have reported that long-term exposure to (comparatively high) levels of estrogen can lead to extinction of fish populations, depending on the species and their life history traits. ${ }^{[8]}$ In the field situation, with concurrent impact of multiple factors and a consequently high baseline variation of influence factors, the population-level effects of chronic, low-dose estrogen exposure cannot be determined within the short observational period of a project like the one presented here. For this reason, we raised population-relevant organismic data in laboratory experiments and then integrated them in a life history specific population model. ${ }^{[9]}$

It was not our aim to identify critical thresholds for estrogenic effects or vital rates, but rather our intent was to estimate (a) if and how changes in individual traits relate to changes in population-level traits, and (b) whether such relations can be detected under conditions of multiple stressors and low dose estrogen exposure. By comparing the model outcomes with actual population measurements, we were then to determine whether there is evidence that estrogens are in fact a population-relevant stressor for brown trout in Switzerland.

To achieve the aforementioned aims, we divided our project into four steps with differing approaches. In the following, we use these as a framework to lead the reader through our project.

\section{Step I: Acquiring Field Data on Estrogenicity of Water Samples and Wild Brown Trout in Order to Assess Estrogenic Exposure in Switzerland}

We measured the estrogenic exposure of river water and wild brown trout downstream of sewage treatment plants (STP) in small- to medium-sized Swiss midland rivers. The selection of the rivers was based on previous studies dealing with estrogens in Swiss rivers. ${ }^{[2,10]}$ Environmental estrogens were measured bioanalytically using an in vitro yeast-based reporter gene assay (YES). This assay measures the total estrogen-like activity in a sample, but does not provide information on what compounds are responsible for the activity. YES-detectable estrogenicity was expressed as $17 \beta$-estradiol equivalents (EEQ). ${ }^{[11]}$ In order to obtain information on the chemical nature of the estrogen-active substances in the samples, LC-MS/MS trace analysis was subsequently used. ${ }^{[12]}$ The investigation of 18 independent river systems allowed characterization of a large set of independent, but similar, sites. ${ }^{[13]}$ The results from this survey indicated that environmental concentrations of estrogen-active compounds in Swiss midland rivers are low ( $<1 \mathrm{ng} E E Q / \mathrm{l})$. However, there are sites that show reoccurring higher values ( $>2 \mathrm{ng} / \mathrm{l}$ ). From over 200 samples analyzed, in less than $4 \%$ did EEQ values exceed $3 \mathrm{ng} / \mathrm{l}$ and the maximum value was $12 \mathrm{ng} / \mathrm{l}$. Grab samples taken along one selected study river, the Lützelmurg (a cold water stream populated by brown trout in Canton Thurgau) indicated no significant sources of estrogens upstream of STP, but consistently found estrogenic activity downstream of the STP. ${ }^{[14]}$ Importantly, levels of estrogenic activity in river water were highly variable over the day and over the year. ${ }^{[14]}$ The main estrogenic analyte detected in river water was estrone (E1) while concentrations of $17 \beta$-estradiol (E2) were often low or undetectable.

The variation of estrogenic levels in grab samples of river water can be partly explained by flow rates: variation tends to increase with decreasing flow rates and increasing effluent load ${ }^{[13]}$ and is linked to the time the wastewater spends in the STP. ${ }^{[14]}$. The effluent estrogenicity is more variable than the dilution factor and appears to be the main parameter that drives variability in the estrogenicity of the river water. ${ }^{[14]}$ Winter levels were fairly constant in respect to estrogenicity. In summer, the EEQ values were much more variable, possibly due to the extremely low river flow conditions in our study summer 2003. In general, the measured concentrations are in line with what has been reported from many other countries, ${ }^{[13]}$ although there are countries reporting much higher estrogenicity for some of their rivers. ${ }^{[15]}$

To estimate the average estrogenicity of the rivers during the studied seasons, we compared our data with the outcome of a model based on the average emission of steroidal estrogens per capita in the effluent of a domestic STP. ${ }^{[16]}$ Although the model was developed for UK STP and flow conditions, the model predicts the long-term average estrogenicity in Swiss STP effluents and rivers rather well. The agreement of the observed estrogenicity with the model predictions is good when all data are taken into account.

However, the observed values were in a range of twofold higher and fourfold lower than the modelled data. With regard to the exposure of fish during critical life stages, such as reproduction, this eightfold range may well be relevant and is suggested to be insufficiently refined for the purposes of a local risk assessment. [14]

To get a better handle on the variability of the estrogenicity of river water, we complemented the grab sampling by establishing and using a passive sampling system (polar organic integrative passive sampler POCIS). Considering the flow rate and the estimated sampling rate, the level of estrogens downstream of the STP in the Lützelmurg was close to what we expected on the basis of the overall average EEQ value of the grab samples (Fig. 1). When studying the estrogenicity along the entire length of the river with POCIS, two thirds of the reduction in estrogenicity was explained by mere dilution whereas the

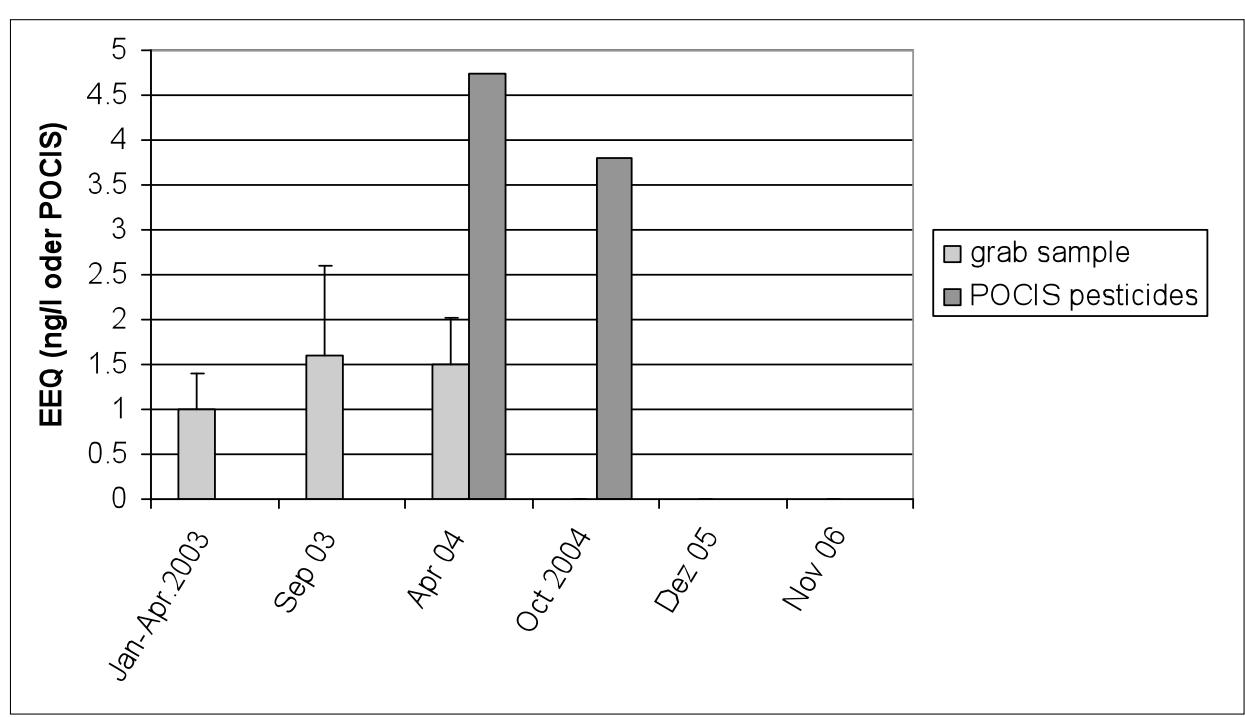

Fig. 1. EEQ values of water grab samples (grey) and POCIS (black) from the river Lützelmurg during the course of the study 
remaining third was presumably due to either sorption or biodegradation. Compared to grab sampling, POCIS integrates over time and is useful for examining the elimination rates of estrogens along the river. Thus, the difficulty of capturing average exposure with grab samples, due to variable flow rates and fluctuating emissions, can be eluded and more reliable statements regarding average estrogenicity of river water can be made. ${ }^{[14]}$

In parallel to the passive samplers, we used caged fish to investigate the bioaccumulation of estrogenic substances in bile. The results showed that POCIS data correlated well with estrogenicity found in bile and that these devices provide an integrated and biologically meaningful measure of estrogenicity. ${ }^{[12]}$ For this active survey, we developed a method of caging brown trout individually in steel tubes. This avoids direct contact between aggressive individuals, thereby reducing injuries and spread of infection. Further, small cages can be easily installed and fixed in our shallow river sites, which are often characterized by extreme peak events and devastating floods. This mini-caging method provided satisfying results in that no mortality and good health was found after three weeks of exposure and no tubes were lost. ${ }^{[12]}$

Since the YES assay is limited in that it does not embody all the processes and mechanisms that are present in a natural organism, we also applied in vivo measurements in brown trout to assess the exposure situation using the well-established biomarker vitellogenin (VTG). ${ }^{[17]}$ Since in the Lützelmurg we are confronted with variable estrogenic exposure in the low dose range, we applied a multifaceted approach by measuring VTG up- and downstream of the STP both in caged and feral brown trout, and both at the protein and mRNA level.[18] Comparing caged versus wild fish accounts for the confounding influence of migration and individual life history, and comparing VTG mRNA versus VTG protein accounts for different kinetics of induction and depuration of VTG protein and mRNA. ${ }^{[19,20]}$ The outcome of VTG biomarker measurements varied with the analytical detection method (protein versus mRNA) and with the exposure modus (caged versus feral brown trout). The clearly higher estrogenicity at the downstream site was reflected in caged male brown trout in significantly elevated hepatic levels of VTG mRNA, but not on the VTG protein level. The situation was different with feral fish. Here, induced VTG protein levels in feral male brown trout corresponded to the higher estrogenicity at the downstream site, whereas VTG mRNA levels showed no site-specific difference. In conclusion, the findings from the comparative analysis of VTG mRNA and protein in caged and feral brown trout indicate that for environmental situations with low and variable estrogenic contamination the correlation between the level of estrogenic exposure and biomarker response strongly depends on the analytical method and the modus of exposure. Therefore, for environmental situations with suspected low and/or variable contamination by estrogen-active substances, a multiple assessment approach may be necessary to estimate the estrogenic exposure in fish. ${ }^{[18]}$ When comparing all VTG protein data acquired during the course of the project, however, the plasma levels were - except for a high value in our first sampling - below $1000 \mathrm{ng} / \mathrm{ml}$.

\section{Step II: Laboratory Experiments to Determine the Sensitivity of Critical Life Stage Parameters to Estrogenic Exposure during (a) Development and (b) Reproduction of Brown Trout and Assessment of the Relevance of Environmental Estrogens in the Context of Other Stressors of Riverine Ecosystems}

We asked the following questions to determine the sensitivity of critical life stages:

- How are developmental and reproductive endpoints altered by transitory or long-term exposure to environmental estrogens in laboratory experiments?

- How do brown trout respond to a combined exposure to estrogen and increased temperature?

- How do trout respond to a combined exposure to estrogen and another important stressor in Swiss rivers, the myxozoan parasite Tetracapsula bryosalmonae?

One potential target, where environmental estrogens may interfere with normal reproductive development and result in gonadal abnormalities is the differentiation process of gonads. Sex differentiation encompasses all the developmental events that take place in the primordial germ cells, including the migration of primordial germ cells, the establishment of gonadal ridges and the differentiation of the gonads proper into testes or ovaries. ${ }^{[21]}$ Sexual differentiation in fish is characterized by a period of increased sensitivity to disruption by exogenous sex steroids in early development. ${ }^{22]}$ During this labile period, the normal development of the gonad could be disrupted. The time in early development when gonads are responsive to organizing effect of exogenous sex steroids varies among the different fish species.[23] Until now, this labile period and with it a critical time window for disruption by estrogens in brown trout has not been known. In closely related species, contrasting ontogenetic periods were identified as the labile period of sexual differentiation: In coho salmon (Oncorhynchus kisutch) and related Pacific salmon species, immersion treatments with E2 resulted in a strong feminising effect if administered to embryos at the time of hatching. ${ }^{[24]}$ In contrast, rainbow trout (Oncorhynchus mykiss) and Atlantic salmon (Salmo salar) were most responsive to exogenous E2 treatment during and after the time of first feeding. ${ }^{[25]}$ On this account, our study with brown trout examined estrogen responsiveness of gonad differentiation both at the embryonic/ hatching stage and during and after the start of exogenous feeding. In addition, the efficiency and persistency of estrogenic impact was estimated by measuring the estrogenic biomarker VTG. Histological analysis revealed that exposure at either period in early development of brown trout did not cause any disruption in the gonadal development. Only by combining both exposure treatments did feminizing effects emerge. Specifically, sex-reversed males were only present when fry were immersed in $400 \mu \mathrm{g} / 1$ E2 after hatch and afterwards received an estrogen diet after onset of feeding until 70 days posthatch. Additionally, intersex gonads, but no evidence for sex reversal, were found in brown trout fed with an estrogenic diet from first feeding until the end of experiment (175 days post hatch). As several related salmonid species under similar exposure conditions at either phase in development showed a strong disruption of gonad development, we assume a different E2 sensitivity of brown trout in early development. Analysis of mRNA levels of the estrogenic biomarker VTG showed that yolk in alevins may act as a reservoir for E2, resulting in exposure to E2 long after the treatment was terminated.

Besides sexual differentiation, reproductive capability is a further important (xeno)estrogenic sensitive target process in fish. ${ }^{[26,27]}$ Therefore, adult brown trout were exposed during gonadal recrudescence and reproduction time to environmentally relevant mixtures of estrogens (E1 and E2) and a commonly occurring estrogenic active substance 4-nonylphenol (NP), ${ }^{[2]}$ to elucidate how reproductive parameters as estrogen-sensitive targets are affected. The ratio of the substances were in the same ratio as detected in the field: E1:E2:NP as 10:1:400 and were applied in a high (100:10:4000) and a low (20:2:400) dose. Subsequently, fertilization experiments with egg and milt of the experimental fish were conducted to study eggs and fry with respect to their fitness.

Of the biometric and reproductive parameters which were measured (condition factor, liver-somatic index, gonadosomatic index, fertility, $\mathrm{VTG}^{[28]}$ ), the liver-somatic index of male fish increased significantly in the high dose experiment. This points to an enhancement of liver metabolism, caused by an increased vitellogenin synthesis in 
the liver, due to preceding exposure to estrogenic endocrine disruptors, as was observed after exposure to estradiol and nonylphenol. ${ }^{[29,30]}$ A significantly lower specific growth rate was observed when females were exposed to high doses compared with control $(\mathrm{p}<0.05)$. The sensitivity of growth parameters was also shown for other fish species, such as fathead minnow and zebrafish where it was stated that this endpoint was highly correlated with reproductive endpoints, such as time to maturation, egg production and fertilization success. ${ }^{[31,32]}$ This may be due energetic constraints as the acclimation to and the metabolism of exogenous estrogens limit the energy available for growth and reproductive processes. There is also evidence that estrogens may directly modulate growth hormones, such as insulin-like growth factors. ${ }^{[33]}$ As well, a significant increase in the percentage of unfertilized eggs was recorded when parent trout were exposed to high doses. A significantly decreased fertility after exposure of male rainbow trout to estradiol was reported at even lower concentrations than those used by us, whereas fertility did not decrease after exposure of females. ${ }^{[34]}$ Although there are some studies suggesting that spermiation might be more sensitive than oogenesis ${ }^{[35]}$ others report the opposite: in the cunner, males continued to produce motile sperms whereas females exhibited a decrease in fecundity when treated with estradiol. ${ }^{[36]}$ However, extrapolation between species has always to be done with caution and the reported differences between the applied substances may have caused differences in reproductive effects as well (EE2 increases the sperm density while E2 decreases it[34,35]).

Only VTG synthesis significantly responded at the low-dose exposure as well, confirming its use as a very sensitive biomarker, but not necessarily pointing to corresponding reproductive effects.

Due to the low estrogenic contamination in Swiss rivers, estrogens alone are probably not sufficient to considerably affect the population. However, estrogenic effects might play a role in context with other stress factors in the ecosystem, such as diseases or temperature increase. This led us to investigate the concert of estrogens and these two factors potentially influencing the reproductive responses, building on previous studies of the concomitant influence of (a) temperature on the biomarker $\mathrm{VTG}^{[37]}$ and (b) the parasite causing PKD on the transcriptomic response of trout and its ability to cope with the parasitic disease. [38]

We know that VTG response is sensitive to stress factors such as temperature increase, and both positive as well as negative relations have been described. [39-41] We have reported a considerable tem-

\begin{tabular}{|c|c|c|c|c|}
\hline & E2 & PKD & E2 and PKD & $\begin{array}{l}\text { Genes } \\
\text { responsible for.. }\end{array}$ \\
\hline TM1 & $\uparrow$ & $\leftrightarrow$ & $\downarrow$ & $\begin{array}{l}\text { Cell } \\
\text { proliferation, } \\
\text { DNAreplication, } \\
\text { energy } \\
\text { metabolism, } \\
\text { protein synthesis } \\
\text { and secretion, } \\
\text { lipid and } \\
\text { oxidative } \\
\text { metabolism }\end{array}$ \\
\hline TM2 & $\downarrow$ & $\downarrow$ & $\downarrow \downarrow$ & \\
\hline TM3 & $\downarrow$ & $\uparrow$ & $\uparrow$ & $\begin{array}{l}\text { Immune system, } \\
\text { innate immune } \\
\text { function }\end{array}$ \\
\hline TM 4 & $\downarrow$ & $\uparrow$ & $\uparrow$ & Immune system \\
\hline
\end{tabular}

Fig. 2. Transcription modules based on the microarray analysis of liver tissue and their response to the exposure of brown trout to PKD and estradiol either alone or in combination

perature increase in alpine and pre-alpine rivers, ${ }^{[42]}$ as well as a VTG response that sometimes deviated from our expectations based on estrogenicity measurements in the river Lützelmurg. ${ }^{[12]}$ Further, differences between plasma protein and mRNA can occur. ${ }^{[18]}$ Therefore, the influence of temperature increase on VTG synthesis was studied in laboratory experiments. ${ }^{[37}$ We also measured stress response as bile cortisol since it is known that chronic exposure to stressors results in a suppression of the reproductive functions. ${ }^{[43]}$ Juvenile brown trout were simultaneously exposed to EE2 (3 ng/l) and low $\left(12{ }^{\circ} \mathrm{C}\right)$, high $(19$ ${ }^{\circ} \mathrm{C}$ ) and fluctuating temperature regimes (12-19 ${ }^{\circ} \mathrm{C}$ ). VTG was measured (plasma protein and mRNA), as well as estrogen receptor ER $\alpha, E R \beta$, glucocorticoid receptor and bile cortisol concentrations. The synthesis of VTG was clearly stimulated under conditions of higher water temperatures and simultaneous estrogen exposure, and the expression of the hepatic ER $\alpha$ was elevated as well. The unchanged bile cortisol concentrations indicate no stress related effects under the conditions tested. ${ }^{[37]}$ In conclusion, the combination of factors occurring under field conditions have to be looked at in more detail to elucidate the mechanisms of (inter)action and thus, consider them appropriately when interpreting biomarker data from the field.

Proliferative kidney disease (PKD) is caused by the myxozoan parasite Tetracapsuloides bryosalmonae and causes high mortality, particularly among young-ofthe year. ${ }^{[44]}$ It has been suggested that infection with pathogens can influence the response of organisms to cope with environmental estrogens. On the other hand, estrogens can affect a range of targets, including the immune system. ${ }^{[33,45,46]}$

If estrogens affect immune parameters in brown trout, then the susceptibility to
PKD could increase and would result in elevated mortalities in river systems. This would imply an indirect effect of (xeno) estrogens. As a consequence, we asked if PKD-induced mortalities of brown trout could be elevated because of concurrent estrogenic exposure. In addition to mortality, we also examined unexpected and multifaceted transcriptomic responses of trout exposed to the combined impact of E2 and an infectious agent, the myxozoan parasite Tetracapsuloides bryosalmonae. The effects of different treatments (food with low dose of E2 $(0.5 \mathrm{mg} / \mathrm{kg})$ or high dose of E2 $(20 \mathrm{mg} / \mathrm{kg})$, PKD infection, PKD infection plus low dose of E2, PKD infection plus high dose of E2) were compared by measuring liver gene expression using a trout cDNA microarray. In addition, the intensity of infection and mortality were recorded. ${ }^{[38]}$ The microarray revealed distinct patterns of molecular response to the individual stressors and their combinations (Fig. 2). Intermediate or additive changes were noted when the two stressors were enforced or counteracted each other, whereas in another pattern, a clear hierarchy between the two stressors was obvious. In the latter, many immune genes were localized which were down regulated by E2 exposure and up-regulated by parasite infection, while in combination, the parasite effect overcame the estrogenic effect. Conclusively, under combined exposure, the fish prioritised the impact of the infective agent over the estrogenic impact. Under cumulative impact of multiple stressors, the organism can respond in a flexible way depending on the nature of the stressor and the pathway affected. ${ }^{[38]}$ With regard to the posed question, we conclude that the mortality observed under conditions of PKD infection only was so high that a further increase due to a concurrent estrogen exposure could not have 
been identified in our experimental set up. Further, our experimental situation is different from the field in that we exposed trout simultaneously to both stressors, whereas in the field, trout must cope with a chronic exposure to (xeno)estrogens and a seasonal challenge to PKD infectious parasite.

\section{Step III: Demography of Wild Fish Population in the River Lützelmurg}

In this part of the project, we aimed at characterising our study river Lützelmurg with regard to the demography of the brown trout populations from upstream and downstream of a sewage treatment plant. Further, we asked how consistent or variable the demographic parameters are over three years. In addition, we studied which of the environmental parameters acting in this river are influencing the demography.

We raised data on the demography of the brown trout population in six selected river stretches, at three upstream and three downstream sites of the STP (Fig. 3). These included density, biomass, age-structure, recruitment (fecundity and redd numbers), condition, growth and migration. The results were then evaluated with respect to the consistency of the demographic parameters over three years, in a total of eight samplings (winter 2003, spring and autumn 2004, spring, autumn and winter 2005, spring and autumn 2006). Abundance and biomass of brown trout decreased along the river course and during our study period. For example, in D2 (Fig. 3) abundance decreased from $1162 \mathrm{Ind} / \mathrm{ha}$ in early winter 2003 to $397 \mathrm{Ind} / \mathrm{ha}$ in winter 2005 and especially the abundance of brown trout $<140 \mathrm{~mm}$ was diminished and disappeared completely in late autumn 2006 in this stretch. As well, the number of redds showed a decreasing trend along the river but was rather stable in both years investigated. Therefore, natural spawning was more important in the upstream sites of the STP. Trout emigration out of the studied river stretches was very low (in summer 0-4 and in winter 0-9 individually tagged brown trout emigrated up- or downstream of the original stretches) and can be neglected in explaining the trends of abundance. The reproduction potential was calculated at the upstream and the downstream part of the river. Although a decrease of the reproduction potential along the river course can be stated, the site directly downstream of the STP (D1) showed the highest reproduction potential in winter $2006\left(5 \mathrm{eggs} / \mathrm{m}^{2}\right)$, because of the highest abundance of ripe females. In contrast, the numbers of redds was low in downstream stretches (20-26 redds/ha). ${ }^{[47]}$

As influencing environmental parameters, proliferative kidney disease PKD, fish species composition, prey abundance

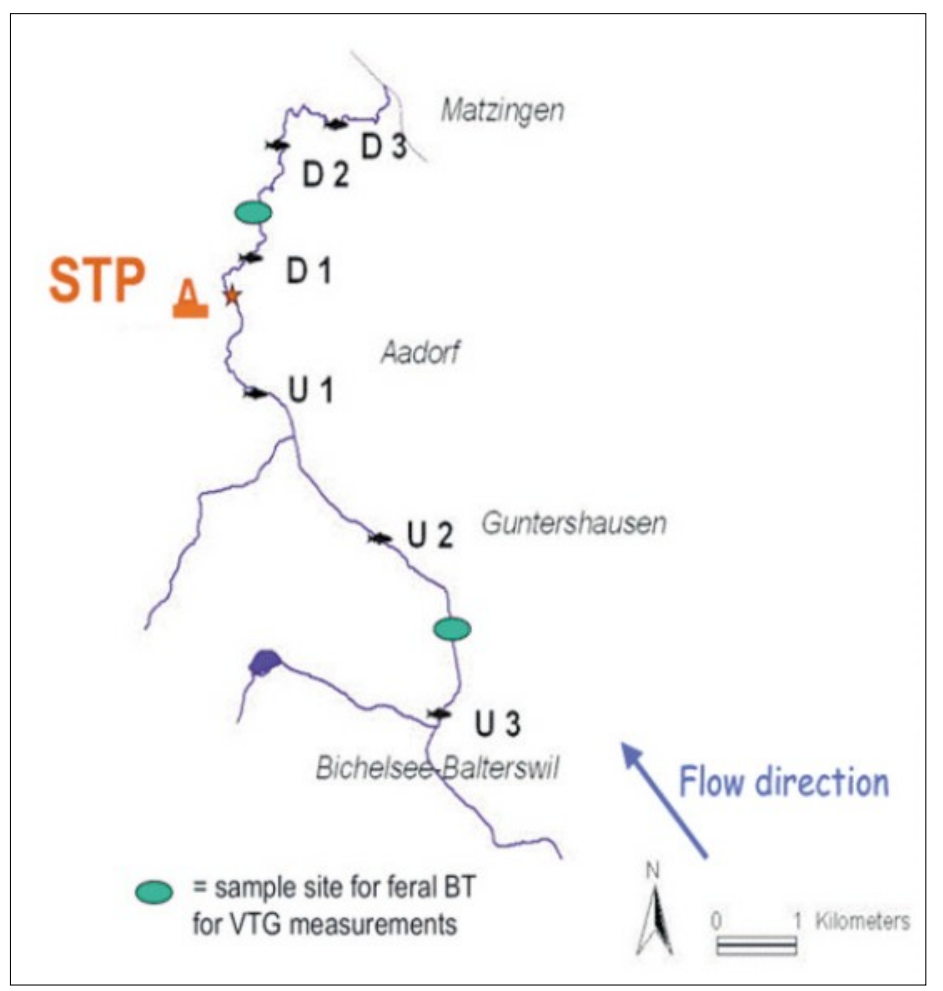

Fig. 3. Lützelmurg, canton Thurgau, with sampling sites upstream (U1-U3) and downstream (D1-D3) of the sewage treatment plant (STP). In addition, at the sites labeled by an ovoid, feral brown trout were caught for vitellogenin measurements

and habitat parameters, including depth, width, river morphology, embeddedness, temperature, stocking and angler success were measured. ${ }^{[47]} \mathrm{A}$ much better condition in the downstream part than upstream was recorded for the food abundance, measured as macrozoobenthos abundance and biomass. Therefore, insufficient food cannot be responsible for the lower fish biomass downstream. Since the coefficient of variation in wetted stream width increased along the river course and other habitat parameters (variation in maximum depth, substrate, cover) document heterogeneity, the variety of the habitat is suggested to be sufficient, both upstream and downstream of the STP and cannot be suspected to cause a decrease in brown trout abundance and biomass. The average temperature did not differ between up- $\left(9.4^{\circ} \mathrm{C}\right)$ and downstream stretches $(9.5$ ${ }^{\circ} \mathrm{C}$ ) of STP over the three years and cannot have differently affected the brown trout population up- and downstream.

To confirm exposure to (xeno)estrogens, VTG and the estrogenicity (E1 and E2 and ethinylestradiol) were recorded. In male brown trout, VTG was significantly induced in specimens downstream of the STP. ${ }^{[13,18]}$ The estrogenic exposure was in the range of concentrations as reported previously, between 0.15 and $0.37 \mathrm{ng} / \mathrm{l}$ for each of the compounds. ${ }^{[12,47]}$

We did not observe a population decline along the river which could be correlated with the estrogenic exposure due to STP effluents. A population collapse was described under chronic, low-dose exposure to 5 ng EE2 over five years in a whole lake experiment in fathead minnow, but not in lake trout. ${ }^{[8,48]}$ We suggest fundamental differences being responsible for these differing results: firstly biological differences among fish species: fathead minnow is a short lived species, most individuals spawn only one season, whereas in salmonids, such as brown trout and lake trout, more spawning seasons are experienced. Although repeated spawners of brown trout have a higher mortality rate due to the spawning activity compared to first-time spawning trout, the overall survival of $65 \%$ for repeat spawners is still high. ${ }^{[49]} \mathrm{A}$ failure of recruitment is more severe in short-lived species than in iteroparous fish species like the brown trout where 2-4 different year classes contribute to the recruitment success. Obvious are species differences in the sensitivity to exogenous estrogens: we never observed gonadal malformations under field conditions. Even under experimental exposure of fry to environmental estrogens, intersex and skewed sex ratio were hardly visible. ${ }^{[50]}$ As well, no loss of age classes or evidence of population decline were stated. Even if we measured increase in VTG in male fish downstream of the STP, the induction factor is smaller than in fathead minnow (ratio between external and internal exposure). This is all in line with results on lake trout in the whole lake experiments. ${ }^{[48]}$ 
A second difference between the Canadian whole lake experiment and our study is the diversity of confounding stress factors we have in our river system, which is typical for many western European aquatic ecosystems. Accordingly, we can assume that endocrine disruption has to be considered in concert with other factors in the system, such as diseases, increased water temperatures ${ }^{[42]}$ and degradation of habitat conditions. ${ }^{[51]}$ To do so, and to assess the possible population-level impacts of the estrogen-sensitive effects we measured in the field and laboratory, we integrated our findings into a dynamic lifecycle model of brown trout.

\section{Step IV: Modelling of Brown Trout Population Effects}

A life cycle model was developed previously for brown trout in Switzerland ${ }^{[9]}$ using Analytica, a commercially available software package for dynamic probabilistic modelling. Further development of the model in the context of this project focused on explicitly representing the potential for reductions in female fecundity, male fertilization capacity, the viability of eggs, the hatching success and early survival of larvae, as well as the potential for changes in survival, age of maturity, and habitat capacity. The response of a population to a particular estrogenic effect will be highly dependent on the entire suite of conditions (natural or anthropogenic) to which a population is exposed. Therefore, we focused our analysis on the upstream and downstream populations of the Lützelmurg that were studied intensively in other parts of our project. The model was parameterized for conditions at these locations using site-specific data on habitat quality, angler catch, stocking, water quality, temperature, and stream bed composition. ${ }^{[47,52]}$ Our goal was to investigate whether endocrine effects would be distinguishable at the level of the population, given the reality of natural variability and uncertain effect levels (Fig. 4).

Elasticity analysis ${ }^{[53]}$ showed that the upstream and downstream populations in the Lützelmurg are both much more sensitive to the survival rate over the first winter and subsequent life stages, than to early life stage survival or reproductive parameters such as fertilization, fecundity, and age of maturity (Fig. 4). In fact, only the adult/juvenile survival rate at the upstream location was found to have a population impact greater than the range of uncertainty and variability in model predictions. This implies that changes in vital rates on the order of $\pm 10 \%$ may not be detectable in the populations given their natural variability and our uncertainty in

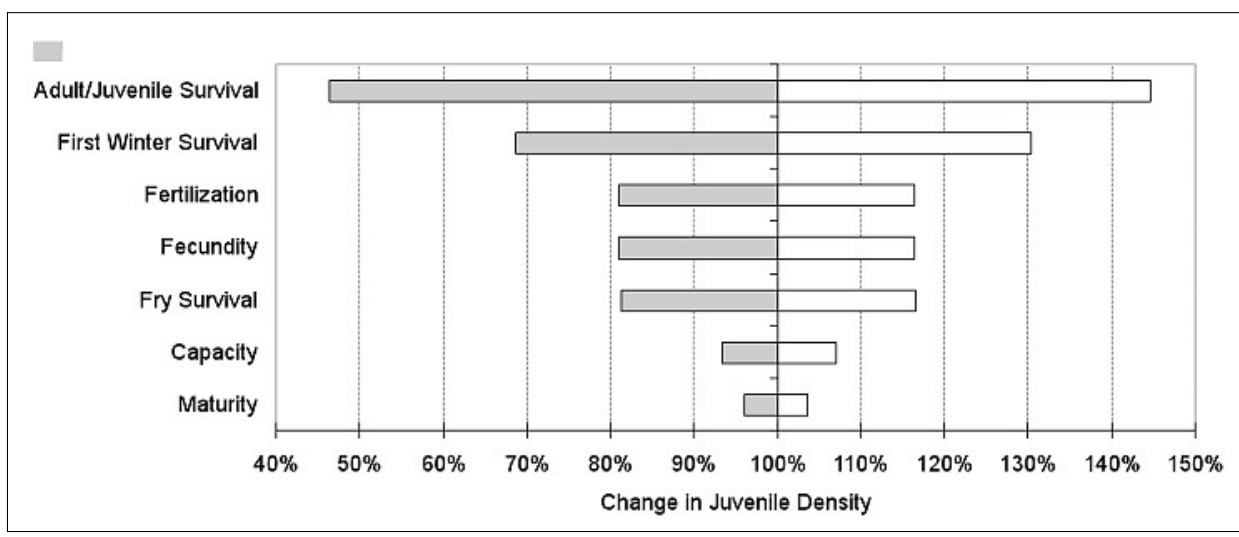

Fig. 4. Elasticity of juvenile brown trout density at the upstream Lützelmurg location to $10 \%$ changes in some key vital rates. Shaded area shows the range in density (70-135\%) associated with natural variability and predictive uncertainty.

understanding the controls on their dynamics. When taken in conjunction with the results of field and laboratory studies, these findings suggest that it may be quite difficult to detect the primarily reproductive effects of endocrine disruptors by monitoring population-level characteristics, such as population growth rate, extinction risk, or abundance. For example, using the model to simulate a $25 \%$ reduction in average fecundity resulted in only a $5 \%$ reduction in the juvenile and adult densities at the downstream Lützelmurg site. This emphasizes the importance of monitoring reproductive variables directly to detect the effects of endocrine disruptors, ${ }^{[54]}$ rather than relying on population density changes alone.

\section{Conclusions}

These results present highlights with far-reaching importance to the whole environmental estrogen disruptor discussion:

i) The exposure situation in Switzerland is moderate at most river sites and the measured concentrations do not seem to lead to direct effects on the reproductive and developmental parameters of wild brown trout that were measured.

ii) Under conditions of low dose and fluctuating exposure as typically observed in many Swiss rivers, other factors such as temperature, chemical pollution, pathogens etc. may strongly modulate or mask the estrogenic response. For example, we reported that estrogenic exposure has an immunosuppressive effect in trout. This complex situation makes a direct association between estrogenic exposure and population status difficult, if not impossible.

iii) An elasticity analysis of our brown trout life cycle model showed that the populations both upstream and downstream of the STP in the Lützelmurg are more sensitive to changes in the survival rates in the first winter and beyond than to the vital rates most likely impacted by estrogenic exposure, such as early life stage survival or reproductive parameters including fertilization, fecundity, and age of maturity. Therefore, it may be quite difficult to detect the effects of endocrine disruptors on populationlevel characteristics, such as population growth rate, extinction risk, or abundance.

iv) Based on our results, the effects of estrogens, via the known estrogen-sensitive mechanisms, are hardly detectable on the level of the population of brown trout in rivers that are exemplified by the Lützelmurg.

\section{Acknowledgements}

Thanks are due to E. Vermeirssen for help in Step I, R. Schönenberger for measuring estrogenicity, the Fishery authorities of Canton Thurgau for help in fish sampling, Yvan Varisco for carrying out first exposure experiments with adult brown trout and to Caroline Joris for population studies.

Received: March 22, 2008

[1] T. Wahli, W. Meier, H. Segner, P. BurkhardtHolm, Histochem. J. 1998, 30, 753.

[2] H. R. Aerni, B. Kobler, B. V. Rutishauser, F. E. Wettstein, R. Fischer, W. Giger, A. Hungerbühler, M. D. Marazuela, A. Peter, R. Schönenberger, A. C. Vögeli, M. J. F. Suter, R. I. L. Eggen, Analyt. Bioanalyt. Chem. 2004, 378, 688.

[3] P. Burkhardt-Holm, A. Peter, H. Segner, Aquat. Sci. 2002, 64, 36.

[4] Fischnetz, Final report of the project 'Fischnetz', Ed. M. Meili. K. Scheurer, O. Schipper, P. Holm, Eawag, BUWAL, Dübendorf and Bern 2004.

[5] T. H. Hutchinson, G.T. Ankley, H. Signer, C. R. Tyler, Environ. Health Persp. 2006 , 114, 106.

[6] J. P. Sumpter, A. C. Johnson, Environ. Sci. Technol. 2005, 39, 4321.

[7] H. Segner, Acta Hydrochim. Hydrobiol. 2005, 33, 17. 
[8] K.A. Kidd, P. J. Blanchfield, K. H. Mills, V. P. Palace, R. E. Evans, M. Lazorchak, R. W. Flick, PNAS 2007, 104, 8897.

[9] M. E. Borsuk, P. Reichert, A. Peter, E. Schager, P. Burkhardt-Holm, Ecol. Model. 2005, 192, 224.

[10] H. Hollert, S. Pawlowski, T. Braunbeck, 'Oekotoxikologische Belastung von Abwasserproben aus dem Kanton Bern/ Schweiz', Zoologisches Institut der Universität Heidelberg, Heidelberg, 2000, p. 80.

[11] E. J. Routledge, J. P. Sumpter, Environ. Tox. Chem. 1996, 15, 241.

[12] E. L. M. Vermeirssen, O. Körner, R. Schönenberger, M.J.-F. Suter, P. BurkhardtHolm, Environ. Sci. Technol. 2005, 39 , 8191.

[13] E. L. M. Vermeirssen, R. Burki, C. Joris, A. Peter, H. Segner, M.J.-F. Suter, P. Burkhardt-Holm, Environ. Toxicol. Chem. 2005, 24, 2226.

[14] E. L. M. Vermeirssen, M. J.-F. Suter, P. Burkhardt-Holm, Environ. Toxicol. Chem. 2006, 25, 2413.

[15] J. H. Shen, B. Gutendorf, H. H. Vahl, L. Shen, J. Westendorf, Toxicol. 2001, 166, 71.

[16] A. C. Johnson, R. J. Williams, Environ. Sci. Technol. 2004, 38, 3649.

[17] J. P. Sumpter, S. Jobling, Environ. Health Perspect. 1995, 103, 173

[18] R. Burki, E. L. M. Vermeirssen, O. Körner, C. Joris, P. Burkhardt-Holm, H. Segner, Environ. Toxicol. Chem. 2006, 25, 2077.

[19] J. A. Craft, M. Brown, K. Dempsey, J. Francey, M. F. Kirby, A. P. Scott, I. Katsiadaki, C. D. Robinson, I. M. Davis, P. Bradac, C. F. Moffat, Mar. Environ. Res. 2004, 58, 419.

[20] S. Scholz, C. Kordes, J. Hamann, H. O. Gutzeit, Mar. Environ. Res. 2004, 57, 235.

[21] J. Bruslé, S. Bruslé, Repro. Nutr. Develom. 1983, 53, 453.

[22] F. Piferrer, S. Zanuy, M. Carrillo, I. I. Solar, R. H. Devlin, E. M. Donaldson, $J$. Experim. Zool. 1994, 270, 255.
[23] F. Piferrer, Aquacult. 2001, 197, 229.

[24] F. Piferrer, E. M. Donaldson, Aquacult. 1989, 77, 251

[25] R. Johnstone, T. H. Simpson, A. F Youngson, Aquacult. 1978, 13, 115.

[26] J. Schwaiger, U. Mallow, H. Ferling, S. Knoerr, T. Braunbeck, W. Kalbfus, R.D. Negele, Aquat. Toxicol. 2002, 59, 177.

[27] D. E. Kime, J. P. Nash, A. P. Scott, Aquacult. 1999, 177, 345.

[28] S. Schubert, A. Peter, R. Burki, R. Schönenberger, M. J.-F. Suter, H. Segner, P. Burkhardt-Holm, in prep.

[29] K. L. Thorpe, T. H. Hutchinson, M. J. Hetheridge, J. P. Sumpter, C. R. Tyler, Environ. Toxicol. Chem. 2000, 19, 2812.

[30] M. Cardinali, F. Maradonna, I. Olivotto, G. Bortoluzzi, G. Mosconi, A. M. PolzonettiMagni, O. Carnevali, Repro. Toxicol. 2004, 18, 597.

[31] R. Länge, T. H. Hutchinson, C. P. Croudace, F. Siegmund, H. Schweinfurth, P. Hampe, G. H. Panter, J. P. Sumpter, Environ. Toxicol. Chem. 2001, 20, 1216.

[32] C. Schäfers, M. Teigeler, A. Wenzel, $J$. Toxicol. Env. Health, A 2007, 70, 1.

[33] H. Segner, E. Eppler, M. Reinecke, in 'Fish Endocrinology', Ed. M. Reinecke, G. Zaccone, B. G. Kapoor, Science Publishers, Enfield (NH), 2006, p. 809.

[34] F. Lahnsteiner, B. Berger, M. Kletzel, T. Weismann, Aquat. Toxicol. 2006, 79, 124.

[35] I. R. Schultz, A. Skillman, J. M. Nicolas, D. G. Cyr, J. J. Nagler, Env. Toxicol. Chem. 2003, 22, 1272 .

[36] R. E. Gutjahr-Gobell, G. E. Zaroogian, J. D. Borsay Horowitz, T. R. Gleason, L. J. Mills, Ecotoxicol. Environm. Saf. 2006 , 63, 244.

[37] O. Körner, S. Kohno, R. Schönenberger, M. J.-F. Suter, K. Knaer, L. J. Guillette, P. Burkhardt-Holm, Aquat. Toxicol. 2008, submitted.

[38] R. Burki, A. Krasnov, K. Bettge, C. E. Rexroad III, S. Afanasyev, M. Antikainen, P. Burkhardt-Holm, T. Wahli, H. Segner, Environm. Sci. Technol. 2008, submitted.
[39] H. R. King, N. W. Pankhurst, M. Watts, P. M. Pankhurst, J. Fish Biol. 2003, 63, 153.

[40] B. Korsgaard, T. P. Mommsen, R. L. Saunders, Gen. Comp. Endocrinol. 1986 , 62, 193.

[41] M. E. Mackay, C. B. Lazier, Gen. Comp. Endocrinol. 1993, 89, 255.

[42] R. E. Hari, D. M. Livingstone, R. Siber, P. Burkhardt-Holm, H. Güttinger, Global Change Biol. 2006, 12, 10.

[43] S. E. Wendelaar Bonga, Physiol. Rev. 1997, 77, 591.

[44] E.U. Canning, A. Curry, S.W. Feist, M. Longshaw, B. Okamura, Bull. Europ. Ass. Fish Pathol. 1999, 19, 203.

[45] S. Ansar Ahmed, B. Hissong, D. Verthelyi, K. Donner, K. Becker, E. KarpuzogluSahin, Environ. Health Perspect. 1999, 107, 681 .

[46] J. T. Martin, Eur. J. Pharmacol. 2000, 405, 251.

[47] S. Schubert, A. Peter, R. Burki, R. Schönenberger, M. J.-F. Suter, H. Segner, P. Burkhardt-Holm, in prep.

[48] J. Werner, V. P. Palace, K. G. Wautier, K. H. Mills, S. M. Chalanchuk, K. A. Kidd, Sci. Mar. 2006, 70, 59.

[49] O. K. Berg, E. Thronaes, G. Bremset, Can. J. Fish Aquat. Sci. 1998, 55, 47.

[50] R. Burki, P. Burkhardt-Holm, M. J.-F. Suter, R. Schönenberger, H. Segner, in prep.

[51] A. Huusko, T. Yrjänä, Fish. Managem. Ecol. 1997, 4, 453.

[52] M. E. Borsuk, S. Schubert, A. Peter, P. Burkhardt-Holm, unpublished result.

[53] H. A. De Kroon, J. Plaisier, van Groenendael, H. Caswell, Ecol. 1986, 67, 1427.

[54] L. D. Arcand-Hoy, W. H. Benson, Environ. Toxicol. Chem. 1998, 17, 49. 